\title{
COMMENTARY
}

\section{Climate change and rural mental health: a social geographic perspective}

\section{AUTHORS}

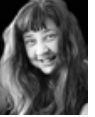

Candice P Boyd ${ }^{1}$ PhD(Psych), PhD(Geog/Creative Arts), ARC DECRA Fellow * , cboyd@unimelb.edu.au

Hester Parr ${ }^{2}$ PhD(Geog), Professor of Human Geography

\section{CORRESPONDENCE}

*Dr Candice P Boyd cboyd@unimelb.edu.au

\section{AFFILIATIONS}

${ }^{1}$ School of Geography, University of Melbourne, Vic. 3010, Australia

${ }^{2}$ School of Geographical and Earth Sciences, University of Glasgow, East Quadrangle, Glasgow G12 8QQ, Scotland

\section{PUBLISHED}

1 December 2020 Volume 20 Issue 4

HISTORY

RECEIVED: 29 July 2020

REVISED: 18 October 2020

ACCEPTED: 23 October 2020

\section{CITATION}

Boyd CP, Parr H. Climate change and rural mental health: a social geographic perspective. Rural and Remote Health 2020; $20: 6337$. https://doi.org/10.22605/RRH6337

\section{ETHICS APPROVAL}

not applicable

This work is licensed under a Creative Commons Attribution 4.0 International Licence

\section{ABSTRACT:}

Context: The objective of this commentary is to suggest ways in which current and future research on climate change and rural mental health can be enhanced by social geographic perspectives. As the effects of climate change escalate, the mental health of rural and remote communities will be placed at increasing risk. As such, it is imperative that academics and practitioners recognise the value of multidisciplinary approaches to tackling this issue. Issues: As social geographers, the authors of this commentary outline concepts from their field that they find helpful in understanding the relationship between people and places, and how these relations give rise to emotions that are responsive to environmental conditions.

Lessons learned: Ultimately, the authors would like to prompt a re-thinking of 'social' as a category, which is usually confined to interpersonal interactions between humans and suggest a broadening of the concept to include both human and non-human worlds. 


\section{Keywords:}

Australia, climate change, earth emotions, ecoanxiety, ecocultural identity, mental health, Scotland, social geography, solastalgia.

\section{FULL ARTICLE:}

\section{Context}

Australia and Scotland (where the authors of this commentary live and work) have rural populations of $29 \%$ and $17 \%$, respectively ${ }^{\mathbf{1}, 2}$. Rural communities in these countries will be the most impacted by climate change, as well as the cities of Brisbane and Edinburgh, whose built environments will also be unduly affected by sea level rise $^{\mathbf{3 , 4}}$. In Australia, the regional areas of the Central Coast in New South Wales, the Sunshine Coast in Queensland, and Greater Shepparton in Victoria are set to experience the highest degrees of hardship due to predicted increases in forest fires, coastal inundation and riverine flooding ${ }^{3}$. In Scotland, warmer and wetter conditions are predicted to bring major inland and coastal flooding, increased coastal erosion, but also alternating drought conditions for rural farming communities. More generally, disruptions to natural habitats and ecologies alongside rising temperatures and unliveable heat are anticipated to bring new and related challenges to both human and non-human communities ${ }^{\mathbf{5}}$.

Surprisingly little research has been conducted on the influence of climate change on mental health ${ }^{\mathbf{6}}$. One notable exception is the work of Helen Berry and colleagues ${ }^{\mathbf{6}, \mathbf{7}}$ who, for more than a decade, have been drawing attention to the need for an overarching framework that incorporates multidisciplinary perspectives. As Berry and colleagues argue, the relationship between climate change and mental health is not a straightforward, linear one $\mathbf{6}^{\mathbf{6}}$, but rather a complex web of interactions that require a systems approach to research and intervention - from large-scale epidemiological studies to groupbased community interventions. For these researchers ${ }^{7}$, the starting point for future research on climate change and mental health is an appreciation that relationships between people and their environments operate at different scales, from individual to collective and from local to global. Ironically, this purview also defines the academic discipline of human geography, of which social geography is a part ${ }^{\mathbf{8}}$.

In this commentary, we (re-)introduce social geography to rural and remote health researchers and practitioners as we did in a commentary in this journal in $2008^{9}$. While the past decade has seen the uptake of social geographic perspectives by rural mental health researchers, particularly in Australia ${ }^{\mathbf{1 0 - 1 2}}$, this understandably takes time. In the context of a global climate change emergency, however, we would like to prompt a re-visiting of what social geography has to offer rural mental health at a time when thinking and doing things differently could not be more important.

\section{What is social geography?}

The origins of social geography as a subdiscipline of human geography have been traced back to the late 19th century. According to the International Encyclopedia of Geography, social geography 'focusses on the relationship between society and space, with particular emphasis on issues related to social identity, nature, relevance, and justice ${ }^{\mathbf{1 3}}$. Throughout most of the 20th century, social geography was concerned with cultures of inclusion and exclusion; that is, how societies were spatially distributed in ways that meant that some groups were advantaged while others were marginalised. Of special interest were issues of gender and sexuality, class, race and racialisation, the geographical displacement of migrants and refugees, and disability (including mental illness) ${ }^{13}$. In terms of rural mental health, social geographers have argued that characteristics of rural communities - such as a culture of self-reliance, a lack of anonymity, rural gossip, and social proximity in general - create barriers to helpseeking and care for people with mental health problems living in these areas ${ }^{\mathbf{1 4}, 15}$

Social geography has developed over time to take up new perspectives and explore new challenges. One of these is identity. As a concept, social geographers now regard identity not as predetermined or fixed but instead something that continually evolves over time through interactions with the environment ${ }^{\mathbf{1 3}}$. This has developed into an area within the discipline known as 'more-than-human' or 'hybrid' geography in which the term 'social' is understood to comprise not just human but also nonhuman entities. As such, the natural world is not 'out there' to meet human needs. As humans, we affect the world at the same time that the world affects us in mutually dependent but also mutually constitutive ways. We are 'of the world' and so our thoughts, feelings, and behaviour simultaneously affect and are affected by what happens in the world. This concept is of particular relevance to climate change as a consequence of the Anthropocene ${ }^{\mathbf{1 6}}$ but is also useful in understanding the relationship between climate change and mental health.

\section{Issues}

\section{Earth emotions and ecocultural identity}

Over the past decade, a new literature of human emotion has emerged from interdisciplinary engagements across the sciences and the humanities ${ }^{\mathbf{1 7}}$, including collaborations between human geographers and neuroscientists ${ }^{\mathbf{1 8}}$. These collaborations challenge two enduring misconceptions: first, that emotions are primarily internal, private experiences ${ }^{\mathbf{1 9}}$ and, second, that neuroscience is a study of the brain in isolation from the rest of the body ${ }^{\mathbf{2 0}}$. In both cases, there has been an increasing appreciation across several academic disciplines that as 'feeling bodies' we are responsive to the social, cultural, political and ecological circumstances within which we live and operate. In other words, our mental health - in fact, our health in general - is co-dependent on the health of the natural environment ${ }^{\mathbf{2 1}}$. As such, chronic impacts on the environment due to climate change are thought to give rise to specific earth-related emotions ${ }^{\mathbf{2 2}}$. 
In what they describe as 'psychoterratic geographies', ecophilosopher Glenn Albrecht in collaboration with human geographers Phil McManus and Raewyn Graham investigated the negative psychological effects of ongoing environmental damage to the Hunter Valley region of New South Wales in Australia ${ }^{23}$. What they ascertained through a formal impact assessment process is that people living in this area were suffering from a kind of trauma related to the chronic deterioration of their natural environment. Experienced as desolation or melancholia, Albrecht refers to this syndrome as solastalgia and argues that it is a similar feeling to nostalgia (or homesickness) but is instead emplaced - an experience of the loss of a place while still living in that place. This is different from, but related to, the concept of ecoanxiety - a sense of impending disaster or doom in relation to the natural world. Both solastalgia and ecoanxiety have been recently recognised and adopted by the American Psychological Association ${ }^{24}$.

Just as collaborations between academic disciplines have helped develop a vocabulary of earth-related emotions, so too have they worked towards a better understanding of psychological wellbeing in relation to climate change. One concept that has proved useful in this regard is ecocultural identity. Scholars in this area created the concept to challenge the Western idea of identity as something that is possessed by a person. Ecocultural identity is not an object but an overarching relation that considers the human 'self' to be always connected to the 'more-than-human' world ${ }^{\mathbf{2 5}}$. As with all identities, ecocultural identity can be positive or negative. The fostering of a positive ecocultural identity, however, has the potential to counteract solastalgia and ecoanxiety by increasing an individual's sense of social responsibility in relation to the earth and thereby their sense of agency in the context of a changing climate.

The emphasis above brings us back to the distinctive contribution of social geography perspectives on rural climate change. 'Climate change' is itself a geographically variegated phenomenon which is differentially understood and experienced by diverse groups of people across a range of places and spaces ${ }^{26}$. Thinking relationally, and with geographical difference in mind, can help us understand climate change and mental health as an evolving and not determined association, which manifests in particular ways in the lives and bodies of rural dwellers. Understanding more about how varied rural environments and human communities manifest climate relations in terms of their 'solastalgic' geographical imaginations and eco-identifications could, therefore, inform new interdisciplinary research agendas in rural and remote health.

\section{Lessons learned}

The hallmark of geographical thinking is that, as humans, we are not separate from the world but embedded relationally within it. Understandings of 'the social' that limit this to a category of solely human interaction perpetuate the false dichotomy between humans and nature that underpins the climate crisis. We would like to suggest that in order to fully apprehend and address the impact of climate change on the mental health of rural communities, we need to extend what 'social' means. Society is a collective coexistence not just between humans but also between humans and the rest of the natural world. While climate change can and will affect the mental health of rural communities, positive ecocultural identity may well prove to be an important protective factor. As social geographers, we urge rural mental health researchers and practitioners to recognise how both human mental health and climate change are relational states. We suggest that a climate change agenda in rural mental health scholarship might seek to interrogate our geographically differentiated psychoterratic futures, particularly with a view to identifying and cultivating empowering connections between people, nature and place.

\section{REFERENCES}

1 Australian Government. Australia's health 2018. 2018. Available: web link (Accessed 6 May 2020).

2 Scottish Government. Rural Scotland key facts 2018. 2018. Available: web link (Accessed 6 May 2020).

3 Mallon K, McKinlay M, Haughton N, Hamden R, Tedder R, Lamb

J. Climate change risk to Australia's built environment: a second pass national assessment. Sydney, NSW: XDI, 2019.

4 Adaptation Sub-Committee of the Committee on Climate Change. UK Climate Change Risk Assessment 2017 Evidence Report - Summary for Scotland. London: Adaptation Sub-Committee of the Committee on Climate Change, 2016.

5 Wreford A, Peace S, Reed M, Bandola-Gill J, Ragne Low R, Cross A. Evidence-informed climate policy: mobilising strategic research and pooling expertise for rapid evidence generation. Climatic Change 2019; 156: 171-190. DOI link

6 Berry HL, Waite TD, Dear KBG, Capon AG, Murray V. The case for systems thinking about climate change and mental health. Nature Climate Change 2018; 8: 282-290. DOI link
7 Berry HL, Bowen K, Kjellstrom T. Climate change and mental health: a causal pathways framework. International Journal of Public Health 2010; 55: 123-132. DOI link, PMid:20033251

8 Lee R, Castree N, Kitchin R, Lawson V, Paasi A, Philo C, et al. The SAGE handbook of human geography. London: SAGE, 2014.

9 Boyd C, Parr H. Social geography and rural mental health research. Rural and Remote Health 2008; 8: 804. Available: web link (Accessed 6 May 2020).

10 Thorsteinsson EB, Ryan SM, Sveinbjornsdottir S. The mediating effects of social support and coping on the stress-depression relationship in rural and urban adolescents. Open Journal of Depression 2013; 2: 1-6. DOI link

11 Wilson R, Cruichshank M, Lea J. Experiences of families who help young rural men with emergent mental health problems in a rural community in New South Wales, Australia. Contemporary Nurse 2012; 2: 167-177. DOI link, PMid:23181369

12 Dolan E, Allot K, Proposch A, Hamilton M, Killackey E. Youth access clinics in Gippsland: barriers and enablers to service 
accessibility in rural settings. Early Intervention in Psychiatry 2020;

14(6): 734-740. DOI link, PMid:32056366

13 Del Casino J. Social geography. In: D Richardson, N Castree, MF Goodchild, et al (Eds). The International Encyclopedia of Geography. New York: Wiley, 2017.

14 Parr H, Philo C. Rural mental health and social geographies of caring. Social and Cultural Geography 2003; 4: 471-488. DOI link

15 Boyd CP, Aisbett DL, Francis K, Kelly M, Newnham K, Newnham $\mathrm{K}$. Issues in rural adolescent mental health in Australia. Rural and Remote Health 2006; 6: 501. Available: web link (Accessed 6 May 2020).

16 Zalasiewicz J, Waters CN, Williams M, Summerhayes CP. The Anthropocene as a geological time unit: a guide to the scientific evidence and current debate. Cambridge: Cambridge University Press, 2019. DOI link

17 Gross DM. Uncomfortable situations: emotions between science and the humanities. Chicago: The University of Chicago Press, 2017. DOI link

18 Callard F, Fitzgerald D. Rethinking interdisciplinarity across the social sciences and neurosciences. New York: Palgrave Macmillan,
2015. DOI link

19 Cromby J. Feeling bodies: embodying psychology. New York: Palgrave Macmillan, 2015. DOI link

20 Burkitt I. Emotions and social relations. London: Sage, 2014. DOI link

21 Hermann JA, Johnson-Walker YJ. Beyond one health: from recognition to results. Hoboken: Wiley, 2018. DOI link

22 Albrecht G. Earth emotions: new words for a new world. Ithaca: Cornell University Press, 2019. DOI link

23 McManus P, Albrecht G, Graham R. Psychoterratic geographies of the Upper Hunter region, Australia. Geoforum 2014; 51: 58-65. DOI link

24 Whitmore-Williams, SC, Manning C, Krygsman K, Speiser M. Mental health and our changing climate: impacts, implications, and guidance. Washington: American Psychological Association and ecoAmerica, 2017.

25 Milstein T, Castro-Sotmayor J (Eds). Routledge handbook of ecocultural identity. New York: Routledge, 2020. DOI link

26 Hulme M. Climate and its changes: a cultural appraisal. Geo: Geography and Environment 2015; 2: 1-11. DOI link

This PDF has been produced for your convenience. Always refer to the live site https://www.rrh.org.au/journal/article/6337 for the Version of Record. 